\title{
Active travel and urban transport: what works and what doesn't - an antipodean perspective
}

\author{
R. Katz \\ Transport Policy Consultant and immediate past president of the \\ Bicycle Federation of Australia, Australia
}

\begin{abstract}
Urban planners have long recognized the desirability of implementing an urban form that promotes active travel in the form of walking, cycling and even public transport. Government and developers have been slower to see the scope for using urban planning as a means of promoting healthy life-styles, environments and economies. However there are now a number of examples of developers and governments working with planners to achieve these aims. Some of the key elements for achieving success include a general consciousness raising and a belief that typical urban form is not immutable. This paper will review some of these examples that show considerable hope for converting at least some of the antipodes to the "pro-peds".

Keywords: active travel, cycling, walking, planning, Australia.
\end{abstract}

\section{Introduction}

This paper aims to provide some tools for policy or facility developers to increase active travel through interventions in a number of decision points. This requires harnessing unusual allies and arguments - some of which may be particular to Australia but many of which are common in all jurisdictions.

\subsection{Questions begged}

Some of the questions that the title raises include:

- What is the meaning of 'active travel'?

- What does 'works' mean?

- Is there a special antipodean perspective?

WIT Transactions on The Built Environment, Vol 89, (C) 2006 WIT Press 
These questions are briefly expanded upon in this section. Subsequent sections consider the 'frames' for dealing with active transport, current strategic issues in promoting it and strategies that can be employed to address perceived hurdles including case studies.

The paper will conclude by answering the questions:

- Can active transport be promoted effectively in the down-under context?

- What are the best ways to do this? and,

- Are these transferable to other places?

\subsection{Active travel}

'Active travel' has been used to describe any mode that incorporates a high proportion of personal energy use (see Mason [1], Bauman et al. [2]). Thus, not only cycling and walking but also public transport has been included in this category. It is a widely used term in the health promotion sector due to the challenge of increased inactivity and high incidence of morbidity and mortality as a result - particularly arising from obesity and overweight.

In Australia, the term 'active travel' has been consistently employed in the health promotion literature as part of a 'settings' approach (see Pikora and Miller [3]) - active travel being the health promotion policy recommended in the 'transport setting' and complementing policies that take place in schools, workplaces etc. The health promotion aspects of cycling in particular have had many proponents (see Andersen et al. [4] and Hillman [5]).

Increasingly, the term active travel is a preferred alternative term to 'nonmotorised', or 'vulnerable' because it avoids an inference of weakness. It is also broad enough to incorporate public transport - unlike human powered transport which has been used from time to time. 'Active travel' has thus been adopted as a marketing brand for modal advocates - cycling, walking and public transport as well as environmental advocates.

The many reasons for promoting active travel are eloquently advanced by Pucher, Mason, Hillman and others (Mason [1], Hillman [5], and Pucher and Dijkstra [6]) and it serves little to repeat them at length here.

\subsection{The meaning of what 'works'}

The apparently simple concept of what 'works' is, like most simple concepts, very hard to pin down Kellen [7]. The language of business would have us measure success in terms of key performance indicators (KPIs) or other measures of effectiveness or efficiency. Even in business where the overall goal (generally profit maximisation for the firm) is a relatively clear, developing and measuring performance is an industry in itself. In social and urban policy it is even more difficult.

For active travel, performance measures are likely to be based around health or environment promotion, or transport efficiency. Some simple KPIs one might expect for active transport are kilometres walked or cycled, trips or mode share by purpose. 
Less direct KPIs include:

- Changes in population health, average weight or BMI, or levels of activity in minutes per day or calorie expenditure;

- Target levels of greenhouse, particulate or noise emissions;

- Energy consumption per kilometre traveled;

For policy makers, planners or managers the real motivators may be quite different. For example they might be:

- Political: i.e. increases in votes or ratings, or reductions in negative comment as a result of appearing to promote active modes;

- Organisational: increases in staff numbers or budget;

- Economic: increased demand or prices for development sites that are well served by active travel modes.

\subsection{An antipodean perspective}

Another factor suggested in the title of this paper is that there is a special antipodean perspective (in this paper antipodean is defined narrowly to be Australian - apologies to New Zealand and other southern hemisphere countries). Some of the factors that characterise Australia from an active travel perspective are:

- Australians, for all their identification with sport, generally lead very sedentary lifestyles leading to internationally high levels of obesity and overweight (Cameron et al. [8], Telford [9]);

- Australia has an historical pattern of suburban development that favours a relatively large 'quarter acre' block style of development;

- Australia has a level of immigration and economic growth that is arguably incompatible with this style of housing in the medium term (Troy [10]);

- Urban environments suffer serious and worsening congestion. The federal minister responsible for transport recently cited government research suggesting that between 2000 and 2020:

- domestic non-bulk road freight will double and the passenger task will grow by $40 \%$;

- urban road tonnages are likely to double; and

- traffic in the major capitals will grow by more than $45 \%$ (Truss [11]).

Arguably, this set of conditions creates especially difficult conditions for promoting active travel while at the same time there are particularly good reasons to support policies in its favour. 


\subsection{The post 9/11 world of planning in Australia}

In last few years there has been a complete rethink about the role of government policy, planning and expenditure as they affect personal and group security. A case in point is the redeployment of people in the Australian Department of Transport and Regional Services from bicycle and pedestrian issues to maritime security. While this has entailed a major diversion of resources, the post $9 / 11$ environment also offers different options for urban planners to introduce reforms that are also in line with their planning goals.

\section{Perspective}

There are many groups of people involved in devising and implementing strategies for active travel. The planner's role is often to mediate these groups.

\subsection{The urban planner's perspective}

Urban planners have a very difficult job. They take on the task of laying out our cities and suburbs in such a way that our bounty is maximised and beauty and harmony is maintained - tasks surely more suited to a deity.

The archetypal planner must therefore have many qualities. They should be able to think architecturally and have a strong aesthetic sense, a good understanding of sustainability issues and the economic and social consequences of urban forms. They also need to be able to negotiate the workings of the political and corporate systems within which development takes place. Perhaps above all, they need to be able to work with and around regulatory and employer frameworks and bring opinion with them. These pressures are summarised in figure 1. below.

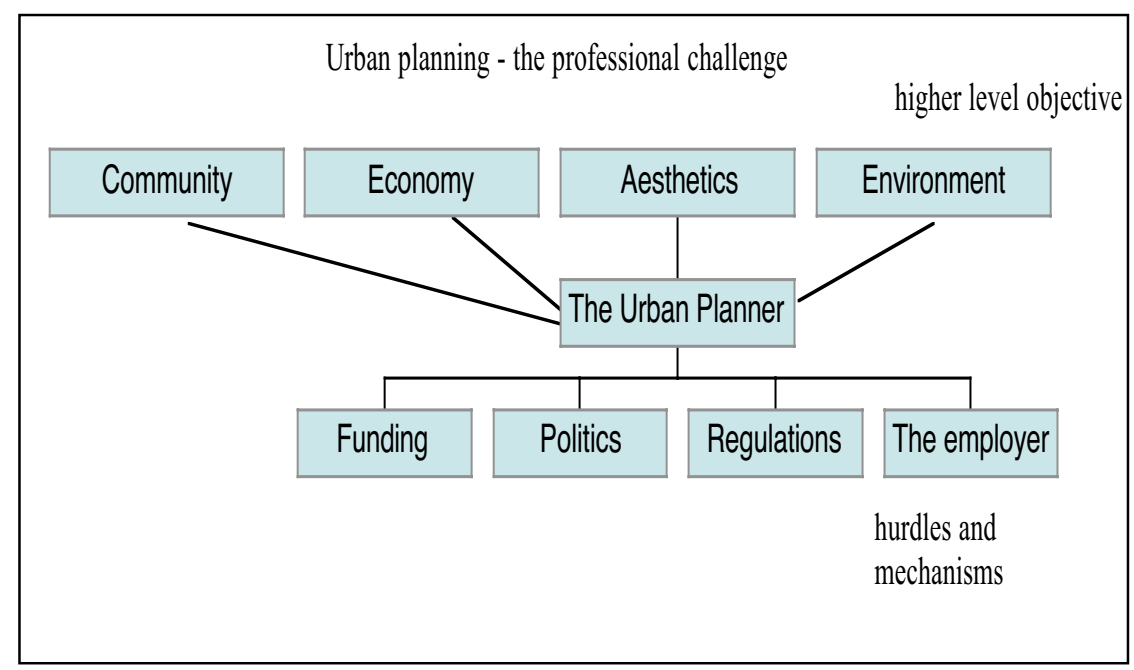

Figure 1: The urban planner's context. 
Training such a talented, principled, yet Machiavellian, person challenges even the most ambitious planning curriculum (see for example University of NSW [12]).

\subsection{A question of time}

Even the most skilled planner must contend with the fact that much of a city's planning is 'path dependent' (see Troy [10]) - the historical, economic and social factors that have played out over tens and even hundreds of years create a natural conservatism or inertia for the planner intent on creating change - sometimes this is a good thing given the many assumptions that we invest in our planning decisions. Even making predictions about population growth is quite difficult. When forecasts seek to incorporate factors such as the future costs of petroleum or other energy sources, the likely value of any carbon emissions permits, congestion charges, technological change, water, road space, housing, commercial rentals, parking, wages, unemployment etc then the future becomes very murky indeed. The role and future of 'fashion' is even harder to speculate.

\subsection{Dealing with density}

Despite these obstacles to planning change, there is a very heated debate about whether we can continue to grow our cities at the current density levels. On this there is clearly no such thing as an antipodean perspective. The antipodes probably has the strongest polar expressions of views on the density debate as exist anywhere. Patrick Troy (see Troy [10]) and Peter Newman (Newman and Kenworthy [13]) are well known protagonists in the area and take diametrically opposed positions on the need for increased urban density.

Troy points out the advantages of larger blocks in terms of the preference sets of Australians and their potential utility for personal production of food, energy and capture of water - a vital issue for a dry continent. Rather than increase density he suggests having a population policy to limit the size of our cities. This argument has recently received considerable airplay and is no doubt appealing to conservative values.

Newman and others make the case that higher densities make active transport more competitive - distances are shorter and public transport can serve more people and more destinations at a lower cost.

In addition, recent research in the US (see Xinyu Caoa and Handy [14]) suggests that larger block sizes tend to encourage people to have larger vehicles - light trucks and SUVs which are particularly intimidating for people walking and cycling.

While very relevant to long term planning, an exclusive focus on the density debate tends to ignore the factors that motivate people to participate in active travel in the short term. As noted by many commentators (see for example Rietveld and Daniel [15]), determining what makes people want to use active travel is a multi-factorial problem. Here it is argued that there are strategies available for increasing active travel without completely reshaping our existing cities. 


\section{Strategies for active travel}

This section discusses a number of case studies and strategies for promoting active travel that come out of the contextual analysis above.

\subsection{Using active travel to reduce fear}

Our media highlights the incidents of aggression, street crime and gang activity on top of the pervasive fears about terrorism. Many people's natural response to this may be 'cocooning' a term was popularised in the 1990 s by marketing consultant Faith Popcorn [16].

The increasing popularity of home based entertainment and larger vehicles support the cocooning thesis. People engaging in cocooning may participate less in community activities and seek to fence themselves off from the broader community. This may paradoxically reinforce the actual and perceived levels of aggression and street crime.

It was the community's fear of street crime that motivated a growing Western Australian municipality on the fringe of Perth to promote active travel (see City of Gosnells [17]). Community consultation revealed that the two major concerns of the community were the environment and security. The Council, advised by planning consultants, concluded that improving the municipal path network would address environmental pollution and improve the safety of the local urban fabric by increasing pedestrian movement.

Over a period of five years from 2001-2005 the Council committed its road maintenance budget, its share of federal funding for local roads and some funding from the State government for bicycle facilities to the path development program. The total cost was A\$5 585000 - a significant amount for a local government with limited funding.

The Council planners cleverly sought endorsement of the approach through publicising their efforts and have received awards from prominent and credible organisations such as the Heart Foundation and Cities for Climate Protection Australia. This sort of third party confirmation helps a community (and particularly its political representatives) establish their credentials and helps the planners promote their ideas.

\subsection{Using active travel to sell developments}

The housing and construction industry is one of the most important for Australia's economy. The industry is comprised of a number of specialist segments such as residential, commercial and infrastructure each of which are large employers.

The negotiating position between government and the private sector development industry is in constant flux as property supply, land availability and funding costs are weighed up against design, social and sustainability issues.

There is a trend among large developers to position active transport as a major selling point for their developments - both to purchasers and government. (e.g., Lend Lease-Delfin Hamilton [18]). It is commonplace for advertisements 
for new developments in the particularly fast growing parts of Australia to feature people walking and cycling. This reinforces the image of a quiet, safe, fun place to live.

The Transit-Oriented-Development movement has gained a strong foothold in Australia. A recent conference highlighted the advantages and ways in which planners, government and developers can work to make TOD happen and how to integrate active transport (Planning and Transport Research Centre [19]).

\subsection{Using active travel to create corridors}

Corridors within and between local government areas often run along rivers and creeks. These offer the opportunity to governments and community groups to promote the possibilities of 'green ways', 'linear parks' or other active travel facilities. Examples are the Torrens linear park in Adelaide, the Hawthorn Canal Active Transport Corridor in Sydney (Ashley et al. [20]) and the river-side paths in Brisbane and Perth.

The example of the Hawthorne Canal in Sydney is particularly interesting as it was a re-vegetation and transport project combined. To be able to offer environmental improvement and an important transport link between the harbour suburbs of Balmain and Lilyfield and the inland suburbs of Marrickville, Dulwich Hill at a very low cost was a major factor in its development and ongoing improvement.

\subsection{Travel behaviour change programs - promoting active travel to reduce congestion spending}

The alternative to increasing road capacity, or supply, is through changing demand. Demand changes can come about through changes in variables such as price or travel time or through a voluntary decision to change behaviour. Voluntary behaviour change programs has been trialled extensively in Australia. The Australian Greenhouse Office commissioned a review of 26 these programs. It found larger household based projects routinely show decreases in car use of $4-15 \%$, and rises in use of walking, cycling and public transport (see RED3 [21]).

It would seem likely that voluntary travel behaviour change programs combined with facility improvements for cycling and walking and increased costs of private motor vehicle use through, for example, congestion tolling would generate even greater changes.

\subsection{Providing for future welfare}

One scenario that any planner should envisage is an economic downturn. This is likely to result in an increased demand for low-cost mobility as offered by active travel.

This argument has not yet had much success in the Australian planning environment - perhaps reflecting our optimistic nature and a long period of economic growth that has generated some complacency. However there is some 
evidence starting to emerge that increases in fuel prices are reducing discretionary use of motor vehicles and particularly serve passenger trips for children (A.C. Nielson study reported in AAP [22]). This should prompt policy support for active transport as a welfare tool.

\section{Conclusion}

Australia, in common with most developed English speaking countries, has high rates of inactivity, high levels of perceived aggression in the community (especially towards cyclists and pedestrians on our roads), low-density development that makes access for active travel difficult, a lack of facilities and little provision of education or marketing to encourage active travel.

Despite these challenges there are reasons to be optimistic. To promote active travel in the Australian context requires a good understanding of the economic, institutional, political and cultural factors that are ingrained in the urban environment. It also requires an opportunistic approach to be able to present an active transport solution to a problem as it gains prominence in the media and in people's decision-making processes.

At the current time active travel can be usefully promoted at the local level to address security concerns and as part of health programs, environmental protection programs and congestion management schemes. In the future, there is scope for including active travel facilities and services more widely as a relatively inexpensive way for people to access the things that they want and at the same time develop a healthy lifestyle. As the urban landscape is developed, or redeveloped, transport planners will have the opportunity to provide facilities that better meet the needs of people wanting to use active transport.

Many of the same concerns and opportunities will present themselves in other jurisdictions. They require the energy and skill to convert them into effective programs and projects at the opportune time.

\section{References}

[1] C. Mason. Transport and Health: enroute to a healthier Australia? Medical Journal of Australia.. 172. 230-2. 2000.

[2] A. Bauman, B. Bellew, P. Vita, W. Brown and N. Owen. Getting Australia active: towards better practice for the promotion of physical activity. Melbourne. 2002. http:/www.nphp.gov.au/sigpah/gaa/index.htm

[3] T. Pikora and M. Miller. A Report On A Pilot Study To Develop A Portfolio Of Interventions To Increase Physical Activity In The Transport Setting. A Project Of Sigpah And The National Public Health Partnership. 2001 .

[4] L. B. Andersen, P. Schnohr, M. Schroll and H. O. Hein. All-cause mortality associated with physical activity during leisure time, work, sports and cycling to work. Archives of Internal Medicine. 160. 2000. 
[5] M. Hillman. Cycling Towards Health and Safety. Oxford University Press. Oxford. British Medical Association Board of Science Policy Papers. 1992.

[6] J. Pucher and L. Dijkstra. Making Walking and Cycling Safer: Lessons from Europe. Transportation Quarterly. 54. 2000.

[7] V. Kellen. Business Performance Measurement At the Crossroads of Strategy, Decision-Making, Learning and Information Visualization. 2006. 2003. http://www.kellen.net/bpm.htm

[8] A. J. Cameron, T. A. Welborn, P. Z. Zimmet, D. W. Dunstan, N. Owen, J. Salmon, M. Dalton, D. Jolley and J. E. Shaw. Overweight and obesity in Australia: the 1999-2000 Australian Diabetes, Obesity and Lifestyle Study (AusDiab). The Medical Journal of Australia.. 178 427-432. 2003. http://www.mja.com.au/public/issues/178 09 050503/cam10689 fm.html

[9] D. D. Telford. Physical activity and quality of life. Blue Earth Institute. 2004.

[10] P. Troy. The Structure and Form of the Australian City: Prospects for Improved Urban Planning. Brisbane. Griffith University. 2004.

[11] T. H. W. Truss. Keynote Address: Delivering for Australia. Sydney. 2006. http://www.ministers.dotars.gov.au/wtr/speeches/2006/WS01 2006.htm

[12] University of NSW. Bachelor of Planning web-site. Sydney. 2006. http://www.fbe.unsw.edu.au/degrees/bplan/

[13] P. W. G. Newman and J. R. Kenworthy. Sustainability and cities : Overcoming automobile dependence. Island Press. Washington, D. C. 1998. http://lcweb.loc.gov/catdir/toc/98-42239.html

[14] P. L. M. Xinyu Caoa, , and Susan L. Handy. Neighborhood design and vehicle type choice: Evidence from Northern California Transportation Research Part D: Transport and Environment. 11. 133-145. 2005.

[15] P. Rietveld and V. Daniel. Determinants of bicycle use: do municipal policies matter? Transportation Research Part A: Transport and Environment. 38. 531-550. 2004.

[16] F. Popcorn. The Popcorn Report: The Future of Your Company, Your World, Your Life. Collins.. 1992.

[17] City of Gosnells. Walking and cycling promotion in the City of Gosnells. Perth Western Australia. 2003.

[18] T. Hamilton. Planning new or repeating success stories; Is it better the devil you know? QLD Urban Community Manager. Lend Lease Communities. Brisbane. Bicycle Federation of Australia Connecting Cycling Conference. 2005.

[19] Planning and Transport Research Centre. Transit Oriented Development Making it Happen. Conference. Fremantle, Western Australia,. 2005. http://www.patrec.org/conferences/TODJuly2005/TODJuly2005.html

[20] B. Ashley, G. Kuiper and A. Woodward. Hawthorne Canal Active Transport (HCAT) Project. Sydney. 2004. 
140 Urban Transport XII: Urban Transport and the Environment in the 21st Century

[21] RED3. Evaluation of 26 Australian TravelSmart Projects in the ACT, South Australia, Queensland, Victoria and Western Australia 2001-2005. Canberra. Australian Greenhouse Office located in the Department of the Environment and Heritage. 66.2005. http://www.travelsmart.gov.au/publications/evaluation-2005.html

[22] AAP. Driving habits changing to cope with fuel prices. Sydney Morning Herald. March 7. Sydney. 2006. 